\title{
Sports Environment and Sunny Sport Activities in School
}

\author{
Bin $\mathrm{Xu}$ \\ College of Foreign Languages, \\ Northeast Dianli University, \\ Jilin, 132012, China
}

\begin{abstract}
The text explained the concept of environment, sports environment, and school sport environment, stated the components which constitute the school sport environment and school sport- environment's impact on the sunny sport activities through the study way of document materials. The text also put up with the constructive opinions to the construction of school sport environment.
\end{abstract}

Keywords-sunny sport activities, sports environment, schoolyard.

\section{INTRODUCTION}

Any sport activities conduct in a certain sport environment, the occurrence and development of sport activities are influence and conditioned by sport environment. Therefore the school sport is no exception. The Education Ministry, the General Administration of Sport and the Central Committee of the Communist Young League jointed announce to develop the sunny sport in billions of students because of the issue of overall slip of the healthy level in teen students.

They are ready to render more than $85 \%$ students make exercise more than one hour a day. It is a crucial method which raise the physique level the students and promote the quality education in a comprehensive way. At the same time, it is a large scale school sport. However, whether sunny sports can be truly conducted as well as a sustained development, a crucial restrictive condition is the school sport environment. Of course, school sports also have the reaction on surrounding, both of them are of interdependency and mutual influence. Here, we pay attention to discuss the effect and promotion of school sport environment on the school sport.

\section{THE CONCEPT OF SCHOOL SPORT ENVIRONMENT}

It is a must to identify the concept of environment, sport environment and so on before the school sport environment. The environment we usually said is the human's environment. But in the environment science, it refers to the opposite side to the central object and the total materials and power for the central object, or the environment is an object relative to the subject, both of them are of interdependency.[2] therefore, we can know the environment including the natural environment and social environment. Natural environment a biological organism or inorganic(air, land, water, and soil) which influence the human life and production in a direct or indirect way. It is a material foundation for the occurrence, development and survive of the human beings.
Social environment is anoppositive concept for the natural environment that the human created the material production system and its environmental system through the people's long-time social labor. That is to say the social environment is the social scene that belongs to the human's life. It includes the social phenomena, cultural circumstances, social consensus, population and the political as well as economic environment and so on. The essence of sport environment is the environmental problem of sport. That refers to the various causes for the development of sport reacted themselves at the same time. Sport and these causes are mutual independency and influence. So the subject is the sport in the sport environment and the object is the various causes that constitute sport. These objects are the sport environment.

Hence, the definition of the sport environment is the space that surrounded sport and the material and social factors that affect sport in a direct and indirect way. School sport environment is the sum of all the necessary conditions which develop the school sport. The subject is school sport, object is the overall environment that has a mutual existence and effect relationships with the school sport. That includes the material and social environment.

\section{CAMPUS SPORTS ENVIRONMENT}

\section{A. Material environment}

1) The place and equipment of sport teaching

The place includes gym and various sport sites such as ground track field, basketball field, volleyball field as well as the surrounded circumstances in these sites such as the sunshine, air, trees, lawn and so on. The assign and construction of the gym and sites shall consider the overall arrangement of school, besides its place, direction, lighting, ventilate, color, sound, temperature and construction materials shall be appeal to the characteristics and requirements of the students. For instance, the orientation of the ground track field usually should agree the meridian line, the wall color and of gym and ground color of some sport sites usually adopt warm color, because warm color makes people's visual and emotional interest going to the outside and improve the excitability of the central lesion. Instruments include gymnasium mats, parallel and single bars, basketball, football, volleyball, fitness equipment, javelin, discoid and shot. These instruments are the necessary conditions to develop sport teaching activities and finish teaching task. 


\section{2) The sites and equipment of outside class sports}

Sunny sport exercise cannot reach the goal only depends the one or two sport class a week. It is a must to develop abundant and colorful outside sport activities and make it into the education plan. Outer class sport should have the appropriate material environment but we usually ignore it before. An appropriate material environment should have the sites and equipment: school exercise and fitness track. To build the fitness track around school that uses the schoolyard wall. The fitness track shall have the ups, downs, bridge, cave, and cross. We also design the acupuncture point track that can reach the effect of body strength. Both sides pf the track shall have the bars and outside weightlifting, swing, flying rings and other sport equipment and endow it the comprehensive effect so as to make them return the natural nature(walk, run, jump, climb, crawl, cross) as well as develop its integrated effect. Extensive sport is one of the best activities to develop cooperation and team spirit. This item should have two or more students to do. So it is the best project to practice cooperation for college students. They can understand to win the victory is nothing but a team. We can use the arranged rope and the wall of buildings or the steel structure to develop a climbing cliff or a climbing wall. In this way, students can develop the brave and strong quality, and to enrich the school sport cultural life.

Most college schools have the lakes and rivers in the construction of the schoolyard. In the water environment, sport activities are abundant and colorful. We can arrange the kayak, drift, boat, dragon boat and other water entertainment activities, such as the boat games in Cambridge University. Now Tsinghua University and Peking University also have this kind of games.

\section{B. Social environment}

\section{1) School sport tradition and atmosphere}

It refers to a school developed the popular, repeated and relative stable team behaviors in the sport community. It is the part of the school spirit.

A good school sport tradition and atmosphere have a silent transforming influence on the students, which has a fatal role in developing students' attitudes, interest, hobbies, and habit on sport.

\section{2) Harmonious interpersonal relationships}

Most school sport activities are team project which has a high requirement for the initiative and strain capacity. Harmonious interpersonal relationships and relaxed environment help the reach of team capacity and students' activity. That also makes them have an active intellect and develop the inner potential of the students as soon as possible.

\section{3) Personal appealing of teachers}

The sport teachers' glorious vocational merits, training and beautiful action demonstration as well as marvelous organized approach can have a deep impression on the students, and male them influenced the silent transforming as well as attract more students engaged in school sport exercises.

\section{Enlightenment and promoting function of the campus physical environment to student's}

Good tradition and campus sports culture can promote students' sports consciousness, formation the values and exercise habits. It is also good for school years formation of the traditional sports and student in the fierce competition among the spirit of competition, and the brilliant achievements in the competition. These factors for the formation of students' sports consciousness, sports values will produce great enlightenment, at the same time, strongly attract students actively devoted to sports, and gradually the exercise habit. It play an intangible role on moving sunshine sports.

\section{THE CONSTRUCTION AND OPTIMIZATION OF THE CAMPUS PHYSICAL ENVIRONMENT}

\section{A. The principal value, increasing investment}

In fact the international competition of the 21st century is the high quality of national and talent. The socalled high-quality talent, is the beauty aspects of allround development of morality, intelligence and physique. The sports is indispensable important factors in the process of talent training. As a result, the headmaster of the school of all types and at all levels should attach great importance to the construction of campus sports environment, on the policy, system give tilt, increase capital investment, speed up the construction of campus sports physical environment. Put sports environment into the overall construction of the campus.

\section{B. The construction of campus physical environment should implement the people-oriented guiding ideology}

The construction of campus physical environment is to meet the needs of students' physical exercise and sports teaching at first, and then is to provide a place to take exercise for the entire school teachers and school communities around. Therefore, we must first know which kind of sports that the students like, according to the students' interests to the construction of sports environment. According to the statistics providing by Zhang Rudong of state sports general administration of sports science research institute science and technology development center, it suggests that students who like ball games accounted for about $76 \%, 6 \%$ of students like track and field sports, swimming, mountain climbing, sports, dancing, and other physical activity accounted for $18 \%$. These research data scientific and reasonable for us to provide a basis for the construction of campus sports environment.

\section{Construction high level competitive sports, formation sports humanities environment characteristics}

A school should have their own distinctive campus sports development, build a high level, suitable to the actual situation of competitive sports team, form their own campus sports tradition, and formed in the process of the accumulation of traditional sports humanities 
environment of our school. Such as women's, men's volleyball of Beijing University of aeronautics and astronautics, Nankai University, Tsinghua University and Peking University rowing project.

\section{CONCLUSIONS}

Students in the campus life, receive the edification and infection of the campus environment here and there, and a good environment of campus physical education will be motivation, persuasion and suggests the role, promote and enlightenment to the students. It can promote the students to form sports consciousness, sports values, sports ability. The pros and cons of campus sports environment directly or indirectly influence and restricts the development of sunshine sports, affects the adolescents' physical health level. Therefore, the construction of campus sports environment should cause the education administrative departments at all levels and attaches great importance to the principals, take all possible measures to build and optimize the campus sports material environment and humanistic environment, which guarantees the smooth implementation of sunshine sports.

\section{CORRESPONDING AUTHOR}

Bin Xu. College of Foreign Languages, Northeast Dian li University, Jilin, 132012, China. Email:34063479@qq.com.TEL:15843294007

\section{REFERENCES}

[1] Clock Tianlong. Sports economics introduction [M]. Shanghai: Fudan University press, 2004.6.

[2] Michael Liz (USA), Yang Yuming, et al. Sports economics [M]. Beijing: Tsinghua University press, 2003.3.

[3] soar. Psychological expansion training study [J]. Journal of Southwest Jiao Tong University ( SOCIAL SCIENCE EDITION ), 2006, (3): 108 - 111 